Full length article

\title{
Hydraulic lime mortars with antifungal properties
}

\author{
Alexandre Jerónimo $^{\mathrm{a}, *}$, Aires Camões ${ }^{\mathrm{a}}$, Barroso Aguiar ${ }^{\mathrm{a}}$, Nelson Lima ${ }^{\mathrm{b}}$ \\ a Universidade do Minho, Campus de Azurém, 4800-058 Guimarães, Portugal \\ ${ }^{\mathrm{b}}$ CEB-Centre of Biological Engineering, Universidade do Minho, Campus de Gualtar, 4700-320 Braga, Portugal
}

A R T I C L E I N F O

\section{Keywords:}

Nano additives

Mortars

Antifungal

Porosity

\begin{abstract}
A B S T R A C T
The use of lime-based coatings came into disuse with the appearance of cement, a stronger and easier to apply binder. However, cement mortars have proven to be rigid to replace lime mortars. In rehabilitation the use of lime-based mortars has been more frequent. With the increase of this type of works it is expected to increase the application of this type of coatings.

Fungi develop on the surface, inside pores and cracks of walls and ceilings and they play a very important role in the degradation of the quality of the buildings and their interior environment. Inside the buildings, the growth of fungi in wet areas, in addition to hygiene and aesthetic problems can also cause respiratory allergy problems.

This study aimed to develop hydraulic lime mortar incorporating nano additives with antifungal properties. The main objective of this study was to verify the development of fungi in mortars added with nano $\mathrm{TiO}_{2}$. The physical and mechanical characteristics were also verified.

For this, four different compositions were developed. The amount of nano $\mathrm{TiO}_{2}$ was varied. It has been possible to observe that the incorporation of nano $\mathrm{TiO}_{2}$ causes significant differences in properties such as workability, compressive and flexural strength. Some changes observed in the mortars were compensated by varying the dosage of the superplasticizer.

The antifungal properties of nano additivated mortars with $\mathrm{TiO}_{2}$ were verified. The results obtained could be a starting point for a transition from the current antifungal protections to new antifungal protections using nano additives.

This transition of antifungal protection will allow an improvement of the quality of the constructions, the health of the users as well as the environmental quality.
\end{abstract}

\section{Introduction}

\subsection{Mortar coatings}

The first used mortars were discovered in the town of Galilee, now Israel, with $>10,000$ years of existence. Since then its use has been extended, using aerial lime and gypsum as binders, separately or mixed. The first hydraulic mortars were found in the cisterns of Jerusalem, built by the Phoenicians [1].

Portland cement in the early nineteenth century became the preferred binder, replacing hydraulic lime and hydrated lime. Portland cement has some advantages, of which: small at time; ease of handling, preparation and storage at the site; better mechanical behavior. However, the disadvantages of the new material, susceptibility to crack and high rigidity, are beginning to be significant when applied in old buildings in which it exhibits poor behavior [2,3].

In old buildings, due to their historical and aesthetic value, it is advisable, whenever possible, to preserve the coverings instead of replacing them. Sometimes the degradation state of the coating is very high, implying partial/total renewal of the coating [4].

Recent studies were developed that allow the appearance of hydraulic lime, in order to obtain a suitable coating for old and recent buildings, with a good behavior and low cost and seek to increase the use of this material, taking into account the requirements and techniques currently practiced.

\subsection{Nanotechnology}

In construction, nano materials will play an important role in the future (structural applications in ceramics, coatings, metals, composites), as well as in many different areas: cosmetics, information technology, biotechnology, medicine, application of sensors, environmental applications, among many others [5]. Recent developments in nanotechnology have contributed to the involvement of buildings in

\footnotetext{
* Corresponding author.

E-mail addresses: ajaj@sapo.pt (A. Jerónimo), aires@civil.uminho.pt (A. Camões), aguiar@civil.uminho.pt (B. Aguiar), nelson@ie.uminho.pt (N. Lima).
} 
environmental, sustainability/rehabilitation issues. Thus the limitations in building materials are broken with the introduction of nanotechnology as a potentiator of new products with new functionalities [6].

Nanotechnology is considered as one of the main technologies of the future. The term "nanotechnology" is used for the production, analysis or use of products of $<100 \mathrm{~nm}(\mathrm{~nm})$ such as particles, films or tubes in at least one size. At nanoscale materials have new properties very important for the development of new products and applications. In recent years, the use of titanium dioxide $\left(\mathrm{TiO}_{2}\right)$ has attracted considerable attention from the scientific community and the industrial sector due to its characteristics of self-cleaning surfaces and the purification of some atmospheric pollutants $[7,8]$. It is useful for protection against fungi existing in buildings. The biggest advantages are its low cost and easy surface application. Experimental results with nanofibers, which can be applied at the site where the fungi appear or where the appearance of the fungus is predicted, shows that with the addition of silver and copper, good results were obtained for antifungal protection, and useful method of protecting buildings against biological deterioration as an alternative to classical methods (spraying biocides and paints) [9].

Some proposals appeared related to photo catalytic coatings, silver and silica nano particles among others for a reduction of microorganisms in buildings [10,11].

The use of science and technology at the nano-scale with real-world application introduces an innovative character to the production of hydraulic lime mortars, mainly in the improvement introduced to the antifungal properties.

\subsection{Prevention of fungi}

In all regions of the world there are fungi inside the buildings. From moderate to humid climates the fungal communities are dominated by the genus Alternaria, Cladosporium, Epicoccum, among others [12]. Fungi develop on the surface, inside pores and cracks of walls and ceilings and play a very important role in the degradation of the quality of the buildings and their interior environment.

The composition of fungal communities has been characterized in a very simplified way and most analyzes refer to monuments and ancient buildings [13].

Inside the buildings, the growth of fungi in wet areas, in addition to hygiene and aesthetic problems can also cause respiratory allergy problems. The most common symptoms are sore throats, rhinitis, cough, among others. In Wales it has been found that $30-40 \%$ of occupants of "fungal-contaminated" dwellings suffer from asthma. Penicilium and Cladosporium are the predominant fungi inside the dwellings [14]. In a study carried out in the cities of São Paulo and São Bernardo do Campo in Brazil, it was verified that Cladosporium was the most frequent genus, followed by Penicillium and Aspergilus [15].

In Portugal there are no data in the literature on the most frequent fungi in buildings. There are some studies of identification of fungal species in monuments, but outside the building, for example in the Cathedral of Lamego [16].

We can say that fungi of the genus Aspergillus, Penicillun, Cladosporium and alternaria exist in contaminated walls and ceilings in dwellings of the northern part of Portugal. The samples were collected in dwellings between 10 and 35 years of age located in Sendim, Vila Real and Porto, whose materials used in the plaster were gypsum, plasterboard, plaster and tinned plaster [17].

The Cladosporium fungus, collected in buildings in the north of Portugal was used in the present study, because it is considered one of the most "aggressive" and is one of the most identified in the literature on fungi in buildings.

The remediation of places where mould appears and the prevention of its occurrence are present problems due to the effort to improve the internal environment of the buildings. It is known that products with antifungal properties are harmful to the environment and human and animal health, so the industry tries to find better degradable biocides.

\subsection{Plaster mortars}

According to EN 998-1: 2013 [18], plaster mortars are distinguished according to their properties and/or use. The standard does not refer to antifungal properties.

For the purpose of certification, plaster mortars are classified according to the class of compressive strength, water absorption and the defined thermal conductivity, characteristics obtained in accordance with the applicable specification standard.

In the present study, although the main objective was the analysis of the antifungal properties, the mechanical properties of the mortars were also analyzed, namely flexural strength and compression.

\section{Materials, composition and fabrication}

\subsection{Materials}

In this study we used:

Hydraulic lime (NHL 5) as a binder, with a density of $1400 \mathrm{~kg} / \mathrm{m}^{3}$ and particles size under $200 \mu \mathrm{m}$.

The river sand, with a density of $2569 \mathrm{~kg} / \mathrm{m}^{3}$ and the mean particle size of $0,762 \mathrm{~mm}$.

The superplasticizer (SP) used is based on polyacrylate, with a density of $1050 \mathrm{~kg} / \mathrm{m}^{3}$.

Finally, the nano $\mathrm{TiO}_{2}$ with a density of $3800 \mathrm{~kg} / \mathrm{m}^{3}$. Primary particles have a mean diameter of approx. $21 \mathrm{~nm}$. The weigth ratio of anatase and rutile is approximately $80 / 20$.

\subsection{Composition and fabrication}

Four different formulations were developed, which are presented in Table 1. The formulations under study consist of different percentages of $\mathrm{TiO}_{2}$ (2, 4 and 6\%), always having a reference composition, without addition of nano $\mathrm{TiO}_{2}$. Two commercial mortars were also used in final finishing. The use of commercial mortars served only to have a basis of comparison of a material that exists in the market, although in the technical datasheets of the respective mortars not to mention what the characteristics of the sands used, it is verified the use of sand finer than used in the blends developed. The mixing and manufacturing process of the specimens for the determination of the compressive and flexural strengths was carried out according to EN 1015-11 [19]. For each composition, three prismatic specimens with $40 \times 40 \times 160 \mathrm{~mm}^{3}$ were molded.

\section{Results and discussion}

\subsection{Workability}

The workability tests were carried out with the objective of giving a suitable workability to the handling of the developed mortars, having been realized based on the method of the table of spreading, specified

Table 1

Formulation of mortars $\left(\mathrm{kg} / \mathrm{m}^{3}\right)$.

\begin{tabular}{llllll}
\hline Composition & Binder & Sand & SP & $\mathrm{TiO}_{2}$ & Water \\
\hline $\mathrm{A} 0-0 \mathrm{TiO}_{2}$ & 500,00 & 1407,52 & 1,00 & 0,00 & 292,56 \\
$\mathrm{~A} 1-2 \% \mathrm{TiO}_{2}$ & 500,00 & 1399,13 & 1,50 & 10,00 & 292,56 \\
$\mathrm{~A} 2-4 \% \mathrm{TiO}_{2}$ & 500,00 & 1390,74 & 2,00 & 20,00 & 292,56 \\
$\mathrm{~A} 3-6 \% \mathrm{TiO}_{2}$ & 500,00 & 1382,35 & 2,50 & 30,00 & 292,56 \\
$\mathrm{~A} 4-$ commercial mortar 2 & & & & \\
$\mathrm{~A} 5-$ commercial mortar 1 & & & & \\
\hline
\end{tabular}




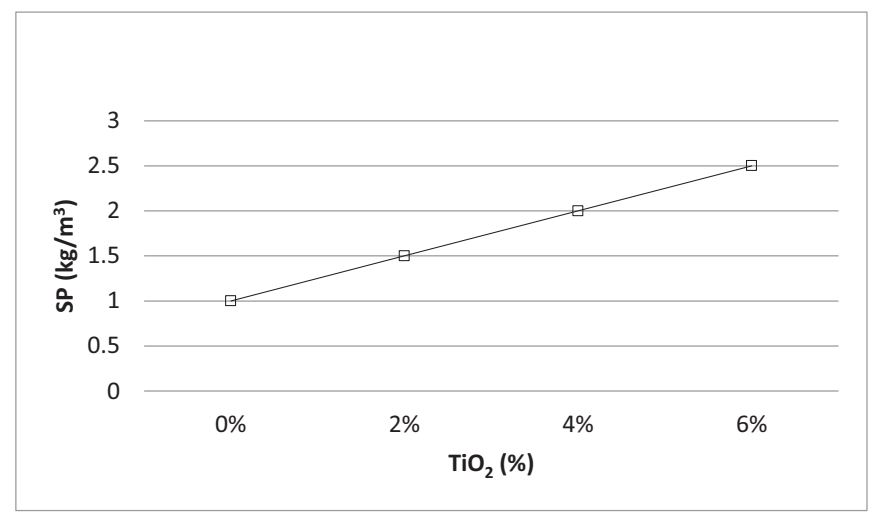

Fig. 1. The increase of the quantity of $\mathrm{TiO}_{2}$ in relation to the increase of the quantity of SP.

by the European standard EN 1015-3 [19]. The resulting value of the test was only considered, when it was between 160 and $180 \mathrm{~mm}$. For samples A0, A1 and A3 a spreading of $175.50 \mathrm{~mm}$ was obtained for sample A2, with a spreading of $175.00 \mathrm{~mm}$. With the increase of the nano TiO2 percentage, it was verified that the workability of the mortar decreases and in order to maintain the workability within the defined values, SP was used. Thus in Fig. 1 we can verify the increase of the quantity of $\mathrm{TiO}_{2}$ in relation to the increase of the quantity of SP able to maintain the workability of formulated mortars in the established parameters. This is due to the fineness of the $\mathrm{TiO}_{2}$.

\subsection{Flexural and compression behavior}

The evaluation of the resistance to the flexion and compression was made based on the European standard EN 1015-11[19], at 28 days of age of the specimens. The specimens were cured in the laboratory at room temperature, hermetically sealed up to 28 days. For the flexural strength, 18 samples ( 3 per mortar) were used and for the compression strength 36 samples (6 per mortar) were used.

For flexural behavior, samples with dimensions of $40 \times 40 \times 160 \mathrm{~mm}^{3}$ were used. The tests were performed with force control at a speed of $50 \mathrm{~N} / \mathrm{s}$. The compressive behavior was evaluated by applying the load on the specimen using a metallic part, sufficiently rigid to uniform the vertical load. The test pieces used for the test were the halves resulting from the flexural tests. The tests were performed with force control at a speed of $150 \mathrm{~N} / \mathrm{s}$. According to Fig. 2, it was possible to observe that with the incorporation of $2 \%$ and $4 \%$ of $\mathrm{TiO}_{2}$ there was an increase in the compressive strength, a slight decrease in relation to the incorporation of $4 \%$ was observed for $6 \% \mathrm{TiO}_{2}$. Fig. 3 shows an increase in the flexural strength with the incorporation of $2 \%$ and $4 \%$ of $\mathrm{TiO}_{2}$, at $6 \%$ of $\mathrm{TiO}_{2}$ there is a slight decrease compared to the incorporation of $4 \%$.

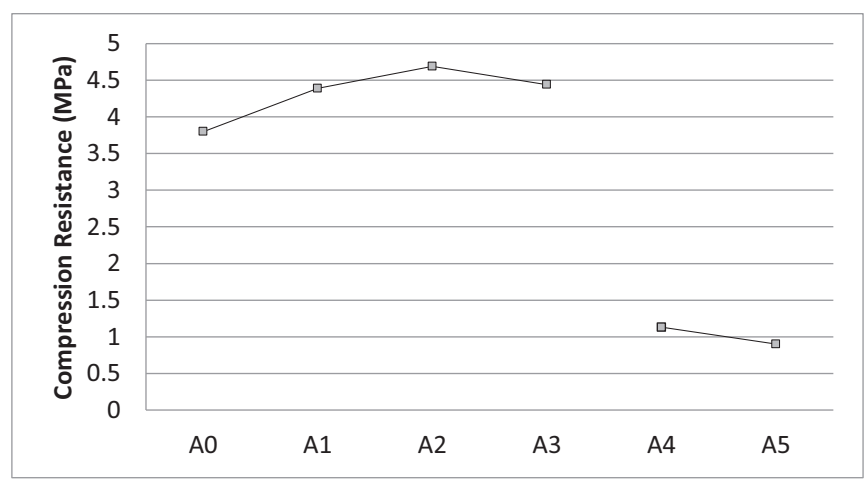

Fig. 2. Compressive behavior of mortar at 28 days.

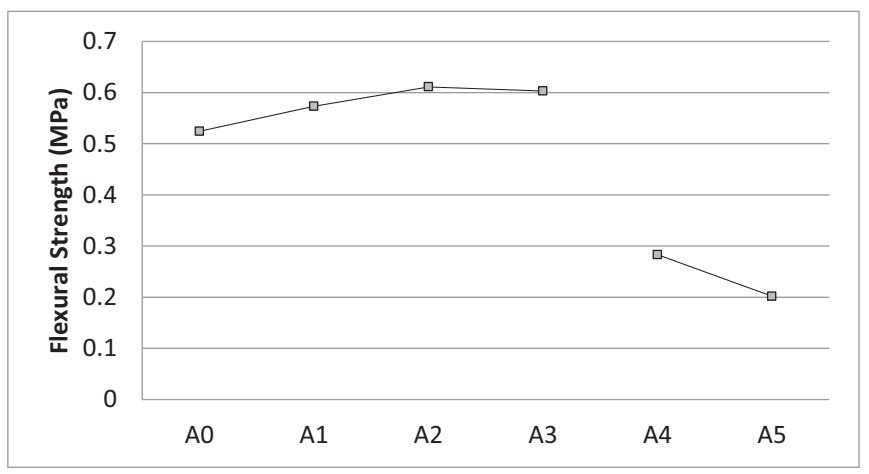

Fig. 3. Flexural behavior of mortar at 28 days.

Table 2

Classification of mortars according to standard NP EN 998-1 2010.

\begin{tabular}{lc}
\hline Classification & Compressive strength \\
\hline CSI & 0.4 a $2.5 \mathrm{MPa}$ \\
CSII & 1.5 a $5.0 \mathrm{MPa}$ \\
CSIII & 3.5 a $7.5 \mathrm{MPa}$ \\
CSIV & $\geq 6.0 \mathrm{MPa}$ \\
\hline
\end{tabular}

Table 3

Classification of mortars according to the compressive strength.

\begin{tabular}{lcc}
\hline Sample & Compressive strength (MPa) & Classification \\
\hline A0 & 3,8 & CSII \\
A1 & 4,39 & CSII \\
A2 & 4,69 & CSII \\
A3 & 4,44 & CSII \\
A4 & 1,13 & CSI \\
A5 & 0,9 & CSI \\
\hline
\end{tabular}

Of note is the increase of $19 \%$ of sample A0 for A2 in relation to compression and $14 \%$ of sample A0 for A2 in relation to flexion.

According to the standard NP EN 998-1, the mortars cam be classified based on the compressive strength Table 2. In Table 3 we verified that the mortars developed are classified as CSII.

\subsection{Accelerated fungal growth}

For accelerated fungi growth, brick samples were prepared according to Fig. 4. Brick masonry is widely used in interior partitions of buildings in Portugal. Despite the control difficulties in larger samples, it is important to have a sample with a sufficient scale to validate the results obtained. After 28 days in the laboratory the samples were sprayed with Cladosporium fungal spores diluted in peptone water at a concentration of $1.26 \times 107$, approximately $3 \times 105 \mathrm{spores} / \mathrm{cm}^{2}$.

Samples were placed in a climatic chamber at $25^{\circ} \mathrm{C}$ and constant relative humidity of $85 \%$. For each sample sprayed with spores was placed a sample without spores (negative test). Three petri dishes (cylindrical vessel, glass or plastic, consisting of a base and a cover used for culture of microorganisms) were placed in the chamber with malt extract agar culture medium (MEA) (positive test) where spores were also sprayed after 3 days, in the petri plates, was already visible the growth of fungi, which confirms the optimal conditions for its evolution.

At 49 days after placement in the climatic chamber, in the visualization with the electronic microscope (SEM), the sample where the evolution of Cladosporium is smaller is in A2, coinciding with the sample that had better physical and mechanical performances.

Fig. 5 shows the growth evolution of the Cladosporium fungus in all the samples. Fig. 6 shows the state of development of the fungi in a 

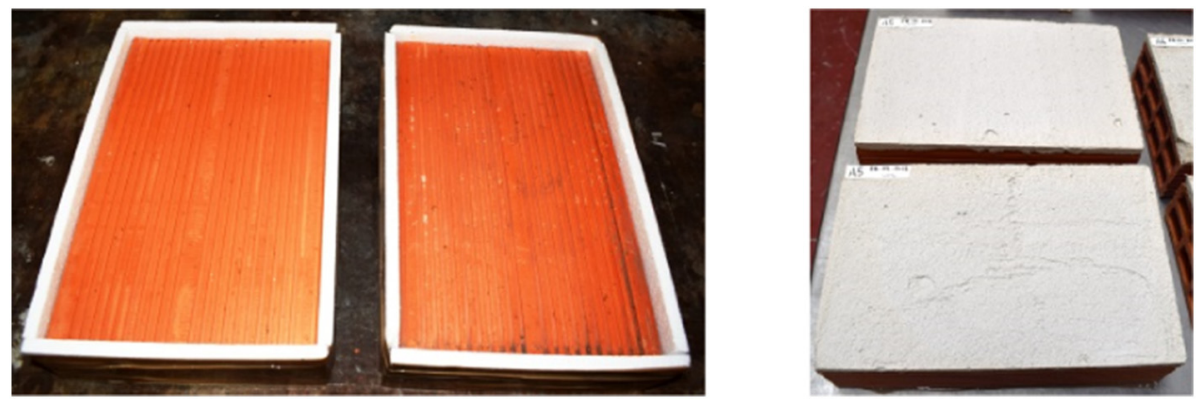

Fig. 4. Preparation of samples (placement of mortar into bricks).

magnification of $3000 \times$. In the sample A0, we verified that the fungus is practically in the whole area, in the sample A3 it is verified $>60 \%$ of the image occupied by the fungus. In sample A1 the fungus begins to develop and in sample A2 the fungus is still practically still to germinate.

The best antifungal performance in sample A2 is justified by the reduction of the porosity of the mortar when we add nano $\mathrm{TiO}_{2}$, also confirmed with the best physical and mechanical performances.

\subsection{Analysis of porosimetry by intrusion of mercury and helium gas}

The pore size and distribution in the mortars were analyzed using the Poremaster 60 mercury porosimeter - from Quantachrome through mercury intrusion porosimetry (MIP), using a pressure range of 0.2396 to $413 \mathrm{MPa}$, which allowed the measurement of the size of pore ratio of $10.64 \mu \mathrm{m}$ to $3.5 \mathrm{~nm}$. An advanced/retreating contact angle of mercury of $140^{\circ}$ and surface tension of $0.480 \mathrm{~N} / \mathrm{m}$ was used in the analysis. Mercury intrusion porosimetry (MIP) is a technique that allows quantifying the percentage and distribution of open pore sizes in a given solid sample. This technique is based on capillary phenomena at controlled pressures, in which the pore is assumed to be capillary, and in the pressure required to apply the mercury to be intruded and fill the pores present as a function of their size, thus allowing the calculation of the distribution of pores open. It allows analyzing a set of parameters related to the open porosity of the materials and products, such as the pore size distribution and the mean diameter and total pore volume.

The total density was determined using unbranded helium pycnometer, built in the chemical engineering department of the Faculty of Engineering of Porto.

In Fig. 7 it is observed that for samples $\mathrm{A} 1$ and $\mathrm{A} 2$ the largest percentage of pores is between diameters 1 and $10 \mu \mathrm{m}(60 \%)$ and $40 \%$ of the pores are smaller. In samples A4 and A5 for commercial mortars the largest percentage of pores is between 1 and $10 \mu \mathrm{m}(85 \%)$ and $15 \%$ of the pores are smaller. And in samples A0 and A3 the smaller pore percentage is between diameters 1 and $10 \mu \mathrm{m}(30 \%)$ and $70 \%$ of the pores are smaller.

In Fig. 8 we observed that in the majority of the samples under study the quantity of larger pores between 7 and $8 \mu \mathrm{m}$ in diameter and the

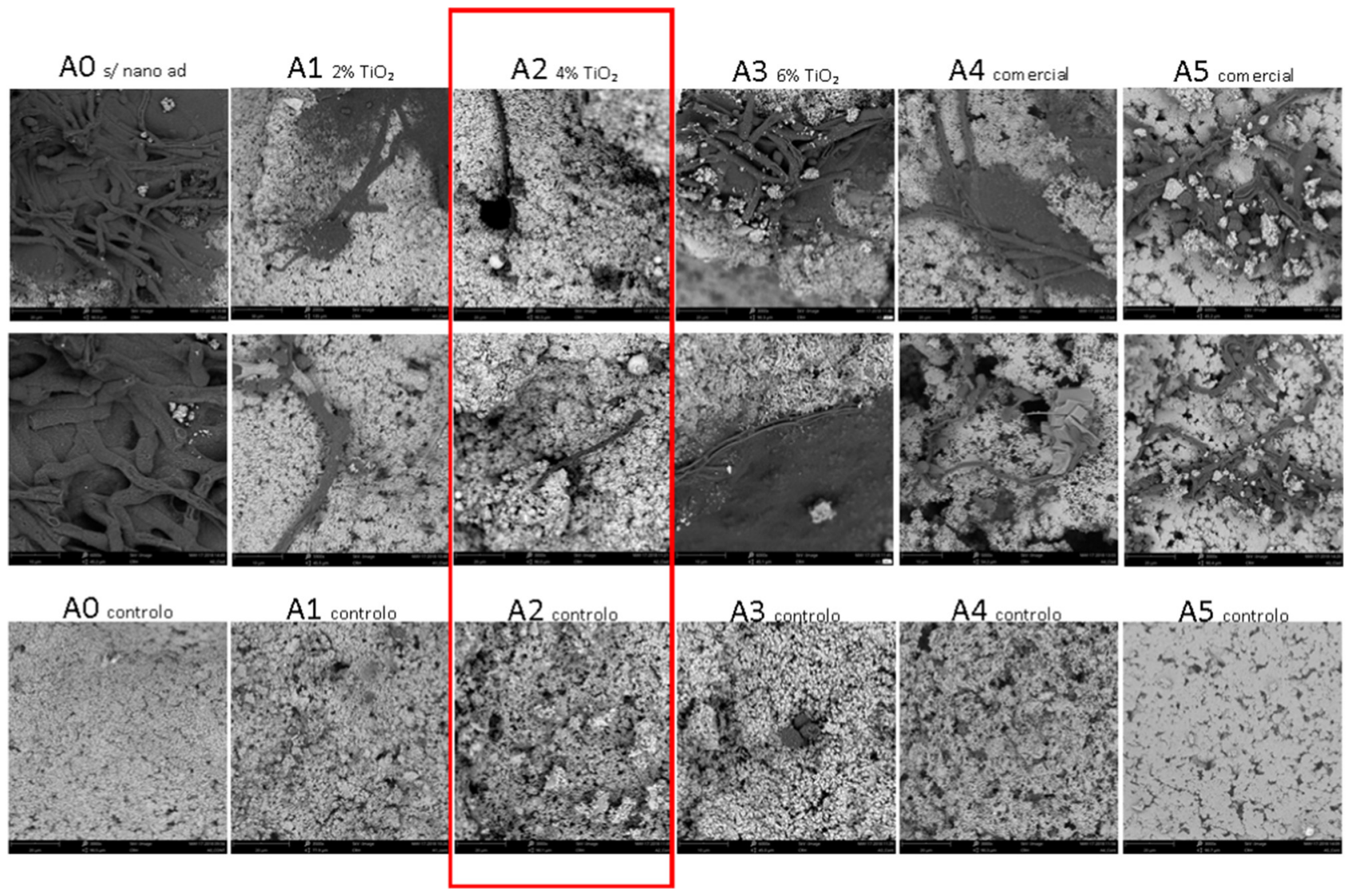

Fig. 5. Images of the samples viewed under the microscope (SEM-3000 $\times$ magnification). 

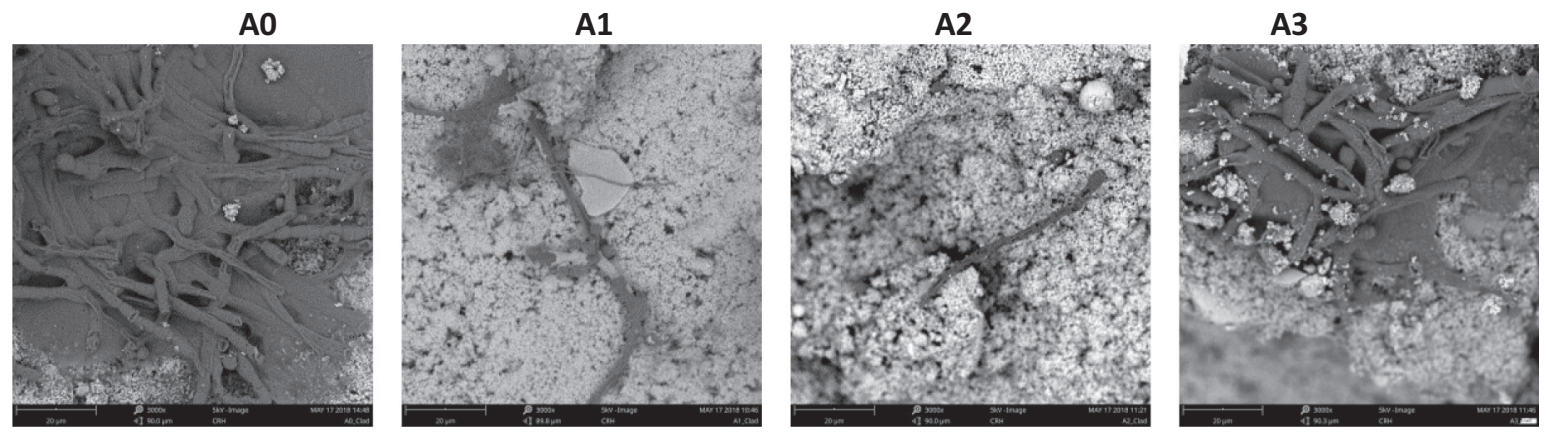

Fig. 6. Development of the Cladosporium fungus in samples A0, A1, A2 and A3 (3000× magnification).

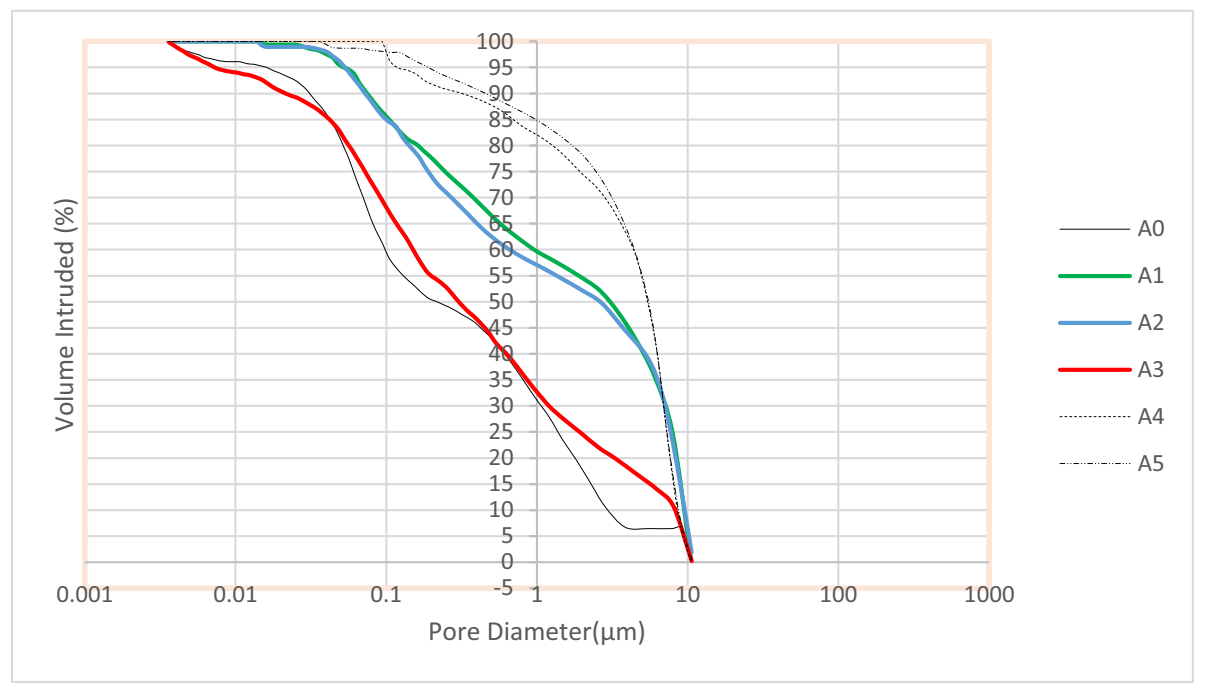

Fig. 7. Percentage of mercury increased in mortars at 180 days.

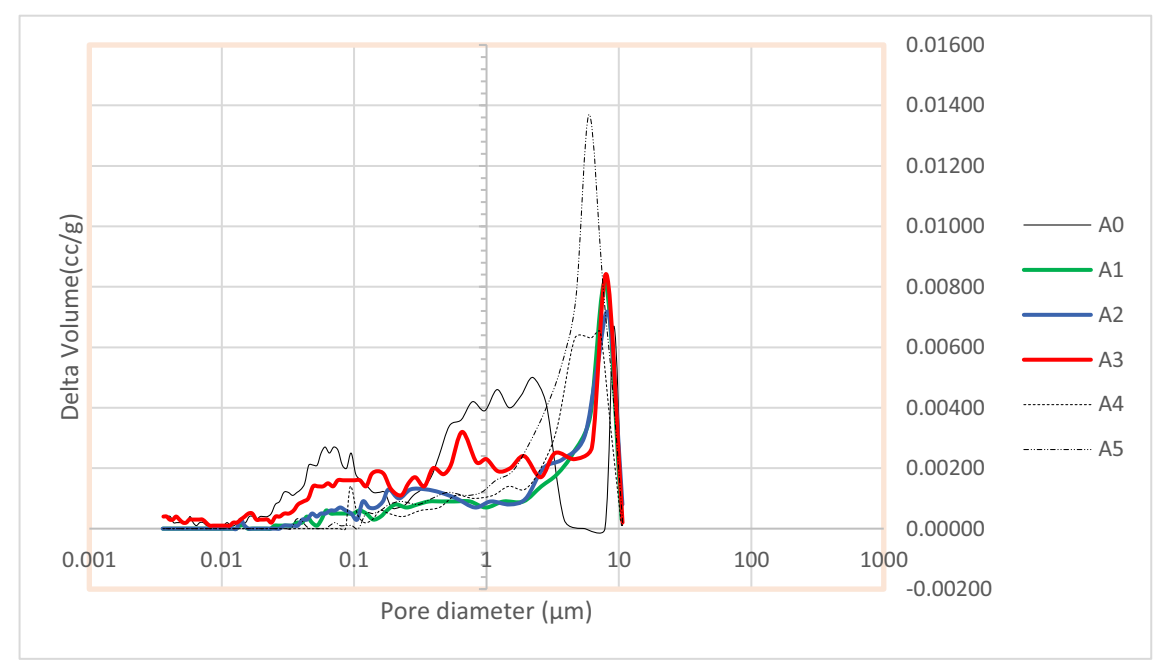

Fig. 8. Amount of mercury increased in mortars at 180 days.

smaller pores between 0.05 and $0.1 \mu \mathrm{m}$ were observed. It is also observed that the increasing introduction of $\mathrm{TiO}_{2}$ implies increasing the percentage of larger pores with 7 to $8 \mu \mathrm{m}$ in diameter and decreasing the percentage of smaller pores.

The total porosity is obtained through the sum between interparticle porosity and intraparticular porosity, as represented schematically in Fig. 9.

Helium gas is used to measure "true density" and "true porosity" also referred to as theoretical porosity, with the assumption that helium, being the smallest atom should be able to penetrate the smallest of pores whereas other fluids may not. Small helium atoms are able to penetrate into the microscopic pores of the samples [21]. This determination measures the porosity of the samples more effectively [20].

However, through the mercury porosimetry test we observed that although the interparticle porosity is lower in the samples A1 and A3, it is verified that the total and theoretical intraparticle porosity (this is obtained through porosimetry to helium), are much higher in samples $\mathrm{A} 1$ and $\mathrm{A} 2$. 


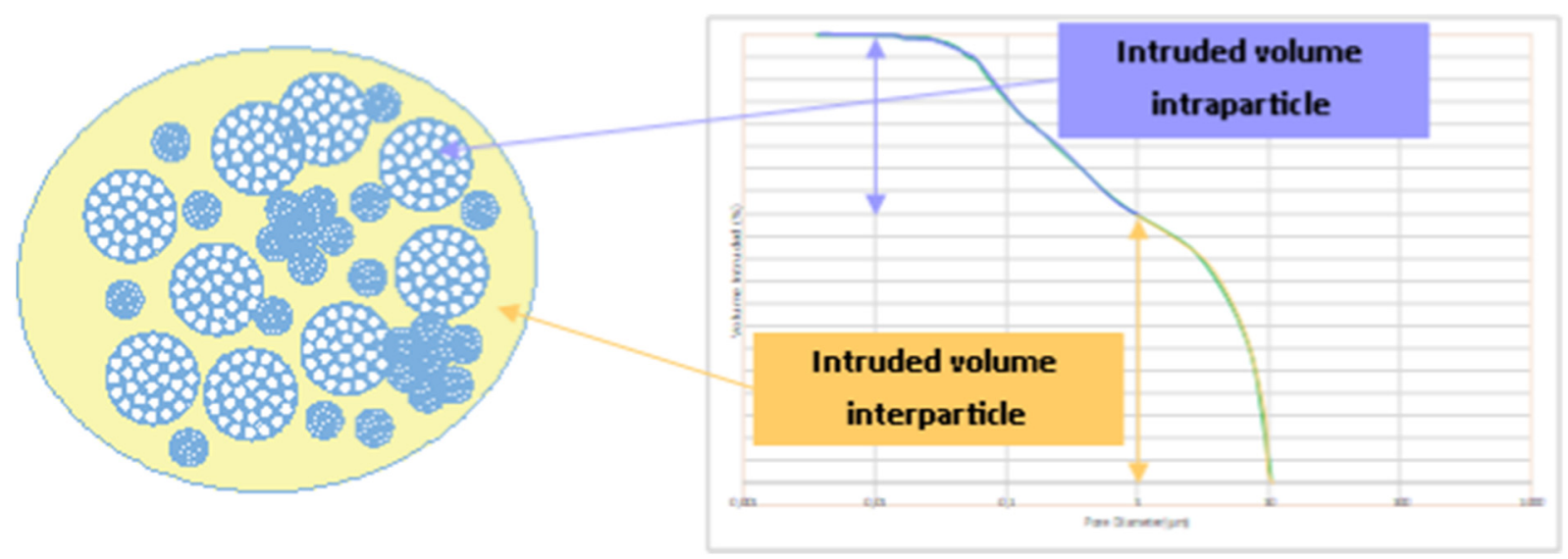

Fig. 9. Porosity Sumamary.

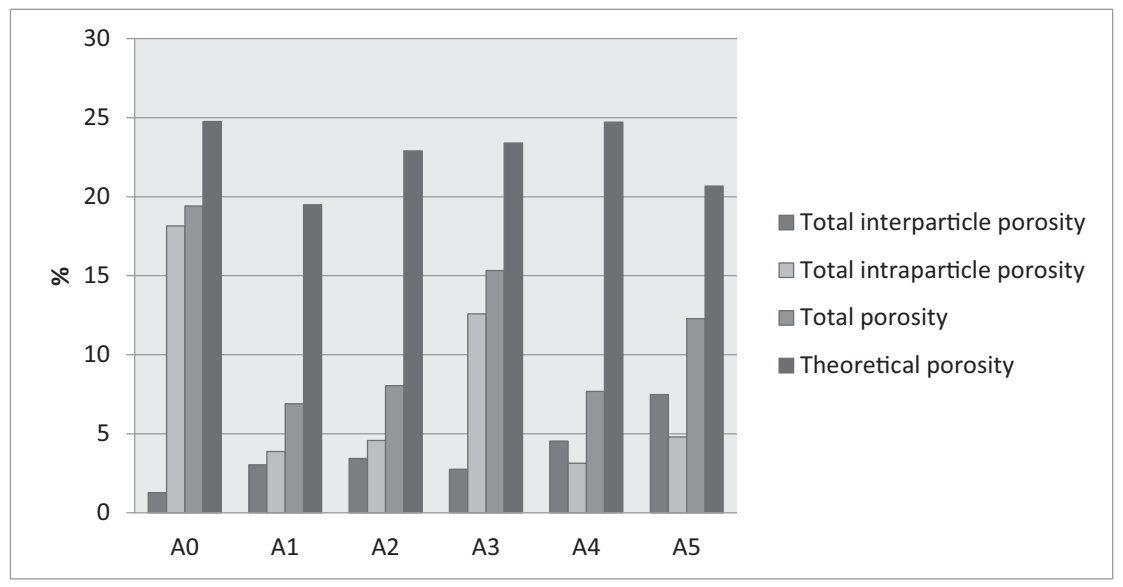

Fig. 10. Porosity of mortar at 180 days.

Table 4

Results of porosity of mortar at 180 days.

\begin{tabular}{|c|c|c|c|c|c|c|}
\hline Code & Samples & Average pore diameter $(\mathrm{nm})$ & Interparticle porosity (\%) & Intraparticle porosity (\%) & Total porosity (\%) & Theoretical porosity (\%) \\
\hline A0 & $0 \% \mathrm{TiO}_{2}$ & 56,60 & 1,27 & 18,15 & 19,42 & 24,75 \\
\hline $\mathrm{A} 1$ & $2 \% \mathrm{TiO}_{2}$ & 247,40 & 3,04 & 3,87 & 6,91 & 19,49 \\
\hline A2 & $4 \% \mathrm{TiO}_{2}$ & 237,00 & 3,45 & 4,59 & 8,03 & 22,90 \\
\hline A3 & $6 \% \mathrm{TiO}_{2}$ & 50,17 & 2,75 & 12,58 & 15,33 & 23,40 \\
\hline A4 & commercial & 913,20 & 4,53 & 3,14 & 7,67 & 24,71 \\
\hline A5 & commercial & 935,60 & 7,49 & 4,80 & 12,29 & 20,67 \\
\hline
\end{tabular}

Samples A1 and A2 have a very close pore structure and in their entirety we can say that they are much less porous than sample A0, this sample having a structure closer to sample A3, as shown by Fig. 10 and Table 4.

The introduction of $\mathrm{TiO}_{2}$ provided greater homogeneity of samples mainly at $\mathrm{A} 1$ and $\mathrm{A} 2$ with a significant reduction of porosity. In the case of sample A3, despite the interparticle porosity being low, a large increase in intraparticulate porosity is warranted due to the increase of fine particles and their difficulty in mixing in the mortar.

\section{Conclusions}

With the accomplishment of this work it was possible to conclude that with the introduction of nano $\mathrm{TiO}_{2}$ the antifungal properties of the mortars are improved.

It will be appreciated that, with respect to the mechanical characteristics, all the compositions conform to the established requirements for mortars.
It was possible to observe that with the nano $\mathrm{TiO}_{2}$ incorporation in the mortars, there was an increase in the compressive strength and the flexural strength up to $4 \%$, for the $6 \%$ it is noticed a slight decrease.

The antifungal properties of $\mathrm{TiO}_{2}$ nano-added mortars achieve their best performance when $4 \%$ of nano- $\mathrm{TiO}_{2}$ is added.

The reduction of the antifungal properties of sample A2 (with $4 \%$ of $\mathrm{TiO}_{2}$ ) for sample $\mathrm{A} 3$ (with $6 \%$ of $\mathrm{TiO}_{2}$ ) is due to the increase of its porosity, mainly intraparticles, which will be associated with the largest number of particles, the difficulty of mixing the mortar.

\section{References}

[1] J. Alavarez, C. Sequeira, M. Costa, Ensinamentos a retirar do passado histórico das argamassas., Em $1^{\circ}$ Congresso Nacional de Argamassas de Construção - APFAC. Lisbon, (2005) (in portuguese).

[2] K. Callebaut, J. Elsen, K. Van Belen, W. Viaene, Nineteenth century hydraulic restoration mortars in the Saint Michael's Church (Leuven, Belgium) Natural hydraulic lime or cement? Cem. Concr. Res. 31 (2001) 397-403 (Leuven).

[3] J. Lanas, J. Pérez Bernal, M.A. Bello, J.I. Alavarez Galindo, Mechanica lproperties of natural hydraulic lime-based mortars, Cement and Concrete Research 34 (2004) 
2191-2201.

[4] M.R. Veiga, J. Aguiar, A.S. Silva, F. Carvalho, Conservação e renovação de revestimentos de paredes de edifícios antigos. CDE 9 ed. Colecção Edifícios - LNEC. Lisbon (in portuguese), (2014).

[5] J.P. Conde, Nanomateriais. Revista Sociedade Portuguesa de Quimica n 97, Junho (2005) 57-59 (in portuguese).

[6] F.v. Broeckhuizen, P.v. Broeckhuizen, Nanotecnology in the European Construction Industry, European Federation of Building and Woodworkers, Amsterdam, 2009.

[7] A. Mathiazhagan, J. Rani, Nanotechnology-a new prospective in organic coating review, Int. J. Chem. Eng. Appl. 2 (4) (2011) 225-237.

[8] A. Mathiazhagan, J. Rani, Nanotechnology-A New Prospective in Organic Coating Review, 2(4) (2011)

[9] Z. Rácová, R. Wasserbauer, P. Ryparová, Microscopic filamentous fungi in buildings, preventing their occurrence and their remediation using nanofibers, Adv. Mater. Res. 649 (2013) 89-92.

[10] C.C. Gaylarde, L.H.G. Morton, K. Loh, M. Shirakawa, Biodeterioration of External Architectural Paint Films - A review, (2011)

[11] C.C. Gaylarde, L.H. Morton, K. Loh, M.A. Shirakawa, C.C. Gaylarde, L.H.G. Morton, K. Loh, M.A. Shirakawa, Biodeterioration of external architectural paint films - a review, Int. Biodeterior. Biodegrad. 65 (2011).

[12] K. Sterflinger, Fungi: their role in deterioration of cultural heritage, Fungal Biol. Rev. 24 (2010) 47-55.

[13] C. Hallmann, et al., Microbial diversity on a marble monument: a case study,
Environ. Earth Sci. 63 (2011) 1701-1711.

[14] R.A. Arthur, C.J. Gregory, I.P. Matthews, The amount of surface mould contamination in homes in South Wales and the prevalence and relative abundance of differing mould genera, II Proceedings of International Society of Indoor Air Quality and Climate, Lisbon, 2006.

[15] M.A. Shirakawa, Biodeterioração de argamassas por fungos: desenvolvimento de teste acelerado para avaliação da bio-receptividade, Instituto de Ciências Biomédicas da Universidade de São Paulo, São Paulo, 1999 (in portuguese).

[16] B.C.C.A. Machado, Caracterização das litogias e patologias da Sé de Lamego - Tese de Doutoramento, Vila Real: UTAD, 2012 (in portuguese).

[17] A. Jerónimo, A. Barroso, N. Lima, R. Eires, Prevenção de fungos em paredes e tetos. $3^{\circ}$ Congresso Luso-Brasileiro de Materiais de Construção Sustentáveis. Coimbra, (2018) (in portuguese).

[18] IPQ, NP EN 998-1, Especificações de argamassas para alvenarias - Parte 1: Argamassas para rebocos interiores e exteriores, s.1.: Instituto Português da Qualidade (ISQ) (in portuguese), (2013).

[19] CEN, EN 1015-11 - "Methods of test for masonry - Part 11: Determination of Flexural and Compressive Strength of Hardened Mortar", s.l, European Committee For Standardization (CEN), 1999.

[20] P. Glover, Porosity, Laval University - PDF, California, 2014

[21] H.H. Schobert, Chemistry of Fossil Fuels and Biofuels, 1st ed., Cambridge UP, Cambridge, 2013, pp. 238-241. 